\title{
Executive Summary of the Korean Society of Nephrology 2021 Clinical Practice Guideline for Optimal Hemodialysis Treatment
}

\author{
Ji Yong Jung ${ }^{1}$, Kyung Don Yoo ${ }^{2}$, Eunjeong Kang ${ }^{3}$, Hee Gyung Kang ${ }^{4}$, Su Hyun Kim ${ }^{5}$, Hyoungnae Kim ${ }^{6}$, \\ Hyo Jin Kim ${ }^{7}$, Tae-Jin Park ${ }^{8}$, Sang Heon Suh ${ }^{9}$, Jong Cheol Jeong ${ }^{10}$, Ji-Young Choi ${ }^{11}$, Young-Hwan Hwang ${ }^{12}$, \\ Miyoung $\mathrm{Choi}^{13}$, Yae Lim Kim ${ }^{14}$, Kook-Hwan $\mathrm{Oh}^{15}$; for the Clinical Practice Guideline Work Group \\ For further information on the authors'affiliations, see Additional information.
}

The Korean Society of Nephrology (KSN) has published a clinical practice guideline (CPG) document for maintenance hemodialysis (HD). The document, 2021 Clinical Practice Guideline on Optimal HD Treatment, is based on an extensive evidence-oriented review of the benefits of preparation, initiation, and maintenance therapy for HD, with the participation of representative experts from the KSN under the methodologists' support for guideline development. It was intended to help clinicians participating in HD treatment make safer and more effective clinical decisions by providing user-friendly guidelines. We hope that this CPG will be meaningful as a recommendation in practice, but not on a regulatory rule basis, as different approaches and treatments may be used by health care providers depending on the individual patient's condition. This CPG consists of eight sections and 15 key questions. Each begins with statements that are graded by the strength of recommendations and quality of the evidence. Each statement is followed by a summary of the evidence supporting the recommendations. There is also a link to full-text documents and lists of the most important reports so that the readers can read further (most of this is available online).

Keywords: Evidence-based practice, GRADE approach, Hemodialysis units, Hospital, Practice guideline

\section{Introduction}

Over the past 60 years, due to the advancement of hemodialysis (HD) technology and the introduction of medical insurance, dialysis treatment has become widespread, enabling many patients with end-stage kidney disease (ESKD) to maintain their lives. The treatment of dialysis patients has also evolved considerably. Depending on the circumstances, various clinical practice guidelines (CPGs) for initiating and maintaining HD have been published internationally. However, the clinical field, the technology of HD, and the target patients covered in previously published CPGs are subject to change. In addition, because the clinical evidence for HD has been reinforced in follow-up studies after

Received: October 18, 2021; Accepted: October 18, 2021

Editor: Tae-Hyun Yoo, Yonsei University, Seoul, Republic of Korea

Correspondence: Kook-Hwan Oh

Division of Nephrology, Department of Internal Medicine, Seoul National University Hospital, 101 Daehak-ro, Jongno-gu, Seoul 03080, Republic of Korea.E-mail:khoh@snu.ac.kr

ORCID: https://orcid.org/ 0000-0001-9525-2179

Copyright (c) 2021 by The Korean Society of Nephrology

(a) This is an Open Access article distributed under the terms of the Creative Commons Attribution Non-Commercial and No Derivatives License (http:// creativecommons.org/licenses/by-nc-nd/4.0/) which permits unrestricted non-commercial use, distribution of the material without any modifications, and reproduction in any medium, provided the original works properly cited. 
the publication of previous CPGs, there is now a demand for reevaluation of these CPGs in accordance with current conditions. In response, the Korean Society of Nephrology (KSN) established the Work Group and tasked it with planning, developing, reviewing, and disseminating appropriate HD treatment guidelines in accordance with international standards. The level of evidence was evaluated using the Grading of Recommendations Assessment Development and Evaluation (GRADE) methodology. The importance of each result is evaluated first, and then the level of evidence for each result is determined as high, moderate, low, or very low. The meaning of each evidence level is shown in Table 1. The recommendation grade was divided into four levels: strong, conditional, against, and inconclusive (Table 2). Key questions that cannot be adapted and developed directly due to poor existing research are expressed as "expert consensus."

\section{Chapter 1. Start of hemodialysis}

\section{Recommendation 1.1}

We recommend that whether and when to start HD be decided through a careful discussion between the patient and the healthcare provider about the benefits/harms of the treatment and the patient's values and preferences about HD initiation because an early start of HD, as determined by the glomerular filtration rate (GFR), in patients with chronic kidney disease (CKD) stage G5 does not produce any differences in clinical outcomes from a late start.

(Strong recommendation, moderate quality of evidence)
When to begin dialysis is influenced by a variety of factors, including signs and symptoms of uremia, biochemical tests, and the patient's GFR. As the precise timing will likely affect the cost of dialysis services and clinical outcomes, certain factors related to mortality, degree of improvement in symptoms and functions, quality of life, and other medical expenses should be considered.

No published studies have investigated the timing of the initiation of dialysis based on patient symptoms. One randomized study (IDEAL; Initiating Dialysis Early and Late) compared the clinical outcomes of relatively earlyand late-starting groups based on GFRs [1], and three subanalyses of this randomized study have been reported [2-4]. Only a comparison between the early-start group and the late-start group based on GFR was available; early $\left(10-14 \mathrm{~mL} / \mathrm{min} / 1.73 \mathrm{~m}^{2}\right)$ and late $\left(5-7 \mathrm{~mL} / \mathrm{min} / 1.73 \mathrm{~m}^{2}\right)$

Table 1. GRADE quality levels of evidence and meaning

\begin{tabular}{ll}
\hline Quality level & Definition \\
\hline High & $\begin{array}{l}\text { We are confident that the estimate of the effect is } \\
\text { close to the actual effect. } \\
\text { Moderate }\end{array}$ \\
The estimates of the effect appear to be close to the \\
actual effect, but it can vary considerably. \\
The confidence in the estimate of the effect is limited. \\
The actual effect could differ significantly from the \\
estimate of the effect.
\end{tabular}

GRADE, Grading of Recommendations Assessment Development and Evaluation.

Table 2. GRADE strength of recommendation and meaning

\begin{tabular}{|c|c|}
\hline Strength & Definition \\
\hline $\begin{array}{l}\text { Strong recommendation } \\
\text { (We recommend) }\end{array}$ & $\begin{array}{l}\text { Considering the benefits and risks of the treatment, the level of evidence, patient values and preferences, } \\
\text { and resources, it is strongly recommended in most clinical situations. }\end{array}$ \\
\hline $\begin{array}{l}\text { Conditional recommendation } \\
\text { (We suggest) }\end{array}$ & $\begin{array}{l}\text { The use of the treatment can vary depending on the clinical situation or patient/social values, so it is recom- } \\
\text { mended for use selectively or conditionally. }\end{array}$ \\
\hline $\begin{array}{l}\text { Against recommendation } \\
\text { (We recommend not) }\end{array}$ & $\begin{array}{l}\text { The risk of the treatment could outweigh the benefit, so taking into account the clinical situation and pa- } \\
\text { tient/social values, implementation is not recommended. }\end{array}$ \\
\hline $\begin{array}{l}\text { Inconclusive } \\
\text { (Data are insufficient) }\end{array}$ & $\begin{array}{l}\text { Considering the benefits and harms of the treatment, patient values and preferences, and resources, the } \\
\text { level of evidence is too low, the scale of benefits/hazards is seriously uncertain, or the variability is so large } \\
\text { that no decision to implement the intervention can reasonably be made. In the absence of a recommenda- } \\
\text { tion or objection to the use of the treatment, clinicians must follow their own judgment. }\end{array}$ \\
\hline $\begin{array}{l}\text { Expert consensus } \\
\text { (We consider it reasonable) }\end{array}$ & $\begin{array}{l}\text { Although clinical evidence is insufficient, the treatment is recommended for use in accordance with clinical } \\
\text { experience and expert consensus, in consideration of the benefits and risks of the treatment, the level of } \\
\text { evidence, patient values and preferences, and resources. }\end{array}$ \\
\hline
\end{tabular}

GRADE, Grading of Recommendations Assessment Development and Evaluation.

Each statement is shown as a combination of the strength of the recommendation and level of evidence.

In the case of a consensus statement based on expert opinion, the recommendation grade and level of evidence are not indicated. 
start times were defined. The analysis found no significant difference between the two groups in major clinical outcomes, such as mortality, quality of life, hospitalization, and infection [1].

In addition, based on various retrospective studies, including domestic research, we synthesized evidence in a meta-analysis [5-14]. After classifying retrospective studies according to design and similarity of selected groups, no benefit or harm was apparent for the relatively early-start patients compared to the late-start group. However, because the heterogeneity between the retrospective studies used in the synthesis of evidence was high, and there was no consistency in the quality evaluation, all were evaluated at a moderate level of evidence.

\section{Recommendation $\mathbf{1 . 2}$}

1. We recommend the preparation of an arteriovenous access prior to HD initiation to avoid central venous catheter insertion. (Strong recommendation, low quality of evidence)

2. We consider it reasonable that the timing of an arteriovenous access preparation be individualized according to patient comorbidities and GFR decline.

(Expert consensus)

The purpose of preparing arteriovenous access for HD using an arteriovenous fistula (AVF) or arteriovenous graft (AVG) is to avoid unnecessary central venous catheter insertion at the timing of dialysis initiation. Central venous catheter insertion may be associated with catheter-related infection, central vein stenosis, pneumothorax, and additional medical expenses, which are typically unnecessary.

Most studies of the preparation of arteriovenous access investigated clinical outcomes by types of arteriovenous access and timing of preparation. No randomized controlled trials have been reported, and most research was observational in nature and based on cohort data. Low mortality and low hospitalization rates were reported in native AVF groups [15-18], but selection bias cannot be excluded due to the nature of the observational studies.

Although survival benefits of patients with a native AVF had been reported in some studies, it has also been associated with maturation failure [17]. Preparation of AVF and AVG has been described as a trade-off for elderly patients. The use of AVGs was superior with respect to maturation, leading to reduced duration of central venous catheter placement and less intervention for delayed vascular access maturation. However, AVG was accompanied by more vascular access abandonment and secondary operation after maturation. Compared to AVG, AVF involved longer vascular access survival and less secondary intervention after maturation.

Although there is no direct evidence regarding the optimal timing of referral of arteriovenous access preparation, the recent Kidney Disease Outcomes Quality Initiative (KDOQI) stated that referral for dialysis access assessment and subsequent creation should occur when the GFR is $15-20 \mathrm{~mL} / \mathrm{min} / 1.73 \mathrm{~m}^{2}$, based on expert opinion. They also stated that earlier referral should occur in patients with unstable and/or rapid rates of GFR decline ( $>10 \mathrm{~mL} / \mathrm{min} /$ year) [19], based on a well-designed Monte Carlo simulation model [20].

\section{Chapter 2. Frequency and dose of hemodialysis}

\section{Recommendation 2.1}

We recommend maintaining a dialysis at a frequency of at least three sessions per week and for 4 hours or more for patients with minimal residual renal function.

(Strong recommendation, moderate quality of evidence)

Since Scribner introduced intermittent maintenance HD in patients with ESKD in 1960, a typical HD schedule has been three sessions for 10-12 hours per week. In Korea, the frequency of dialysis is three sessions a week, for 12 hours. Various frequencies of HD treatments, such as daily home HD sessions, are not mentioned in this guideline due to medical insurance issues in Korea. It is difficult to define the appropriate number and duration of dialysis sessions separately. We therefore examined and summarized related studies about relevant sessions and the time of dialysis.

In two randomized controlled studies of HD patients who received dialysis three times a week, no significant differences in mortality (odds ratio [OR], 1.02; 95\% confidence interval $[\mathrm{CI}], 0.88-1.18 ; \mathrm{p}=0.79$ ) and hospitalization rates (OR, 1.38; 95\% CI, 0.67-2.87; $\mathrm{p}=0.38$ ) were reported between the two groups (patients receiving more than 4 hours and less than 4 hours of HD per session) [21,22]. However, in the four cohort studies in which a meta-analysis was possible, the mortality rate (OR, 1.34; 95\% CI, 1.15- 
1.55; $\mathrm{p}<0.01$ ) was higher in the group receiving less than 4 hours of dialysis compared to the group receiving more than 4 hours [23-26]. Based on these findings, the dialysis frequency in patients with minimal residual renal function should be at least three times a week, with sessions lasting at least 4 hours [27]. Charra et al. [28] reported improved blood pressure control through long HD $(3 \times 8$ hours/ week). Marshall et al. [29] found that the mortality rate was lower among patients receiving more than 4.5 hours of HD per session.

In addition, studies show that it is possible to try initiating twice-weekly HD in patients who retain significant residual kidney function. A meta-analysis of three studies found that the mortality rate tended to increase in HD patients without residual renal function, suggesting it should only be attempted while monitoring carefully for changes in residual renal function [30-32].

\section{Recommendation $\mathbf{2 . 2}$}

We recommend a target dose of 1.4 single-pool Kt/V (spKt/V) for patients receiving thrice-weekly HD.

(Strong recommendation, moderate quality of evidence)

The adequacy of HD has been traditionally measured by evaluating the clearance of small molecules such as urea. Since the advent of the Kt/V measure, which consists of dialyzer clearance $(\mathrm{K})$, dialysis time $(\mathrm{t})$, and volume of distribution (V), many observational studies have consistently reported that dialysis with an increased Kt/V was significantly associated with survival benefits in patients on HD [25,33-42].

The representative study for this issue is the HEMO (Hemodialysis) Study published in 2002 [43]. In this randomized clinical trial involving 1,846 patients undergoing thrice-weekly $\mathrm{HD}$, the high-dose group maintaining a mean spKt/V of 1.71 enjoyed no significant benefit of morbidity and mortality compared to the standard group maintaining a mean spKt/V of 1.32 .

Because the aforementioned observational studies reported that increased mortality was associated with an inadequate dialysis dose, maintaining appropriate dialysis time under a qualified dialysis system is recommended to obtain a spKt/V of 1.4. However, as the HEMO Study showed no improvement in morbidity and mortality with high-dose dialysis, increasing the dialysis dose beyond the recommended level is unnecessary.

The urea reduction ratio (URR) and equilibrated Kt/V $(\mathrm{eKt} / \mathrm{V})$ offer alternatives for assessing dialysis adequacy. The URR is simple and easy to calculate, but does not assess dialysis adequacy accurately because it does not take into account the volume of urea distribution. The eKt/V value is lower than that of spKt/V, because it is calculated by considering the redistribution of urea after dialysis. In the HEMO Study, the mean eKt/V in a standard group maintaining a mean spKt/V of 1.32 was 1.16. In general, the corresponding eKt/V is 1.2 when the targeting dialysis dose of spKt/V is 1.4.

\section{Chapter 3. Dialysis membrane and modality for hemodialysis}

\section{Recommendation 3.1}

We recommend the use of high-flux dialysis membranes in adult HD patients. However, the cost and availability of high-flux membrane need to be considered.

(Strong recommendation, high quality of evidence)

To date, three large-scale randomized clinical trials, the HEMO [43], MPO (Membrane Permeability Outcome) [44], and EGE [45] trials, have compared high- vs. low-flux HD membranes. These trials have not revealed a statistically significant benefit in reducing all-cause death.

However, the HEMO Study [43] reported a significant reduction of cardiovascular (CV) death as a secondary endpoint ( 0.072 vs. 0.059 patient-year), and a significant benefit in the composite outcome defined as CV death and hospitalization due to CV disease. Furthermore, a subgroup analysis showed a significant reduction of mortality risk by $37 \%$ in subgroup of patients treated with dialysis for more than 3.7 years prior to randomization. In the MPO Study [44], a statistically significant reduction in all-cause mortality was evident in the high-flux group compared to the low-flux group among participants with serum albumin equal to or lower than $4 \mathrm{~g} / \mathrm{dL}$ (relative risk [RR], 0.49; 95\% CI, 0.28-0.87). This study also showed that improved survival was associated with high-flux dialyzers among those with diabetes. Although the EGE Study [45] did not show a reduction of composite CV events, post hoc analysis suggested a benefit associated with high- vs. low-flux dialysis membrane on improving CV event-free survival among 
those with AVFs and those with diabetes.

Meta-analysis of 12 prospective clinical trials [43-54] comparing high- vs. low-flux HD membranes, excluding observational studies, showed a $13 \%$ reduction (RR, 0.87; 95\% CI, 0.76-0.99) in all-cause deaths and a $19 \%$ reduction (RR, 0.81; 95\% CI, 0.70-0.95) in CV deaths. Furthermore, $\beta 2$-microglobulin concentrations were reduced by 9.90 $\mathrm{mg} / \mathrm{L}$. However, no differences in hospitalization and Kt/V were shown.

\section{Recommendation 3.2}

1. There was no difference in all-cause mortality, CV mortality, hospitalization rate, and quality of life in online hemodiafiltration (HDF) compared with high-flux HD.

(Conditional recommendation, moderate quality of evidence)

2. We consider it reasonable to apply high-volume online HDF after considering cost-effectiveness in some cases.

(Expert consensus)

In randomized clinical trials comparing online HDF with high-flux HD, including the Turkish OL-HDF (Online Hemodiafiltration) [55] and the FRENCHIE (French Convective vs. Hemodialysis in the Elderly) [56], no significant effect on overall mortality and CV mortality was demonstrated. However, in the Turkish OL-HDF Study, which was divided into two groups with a $17.4 \mathrm{~L}$ (the median amount of supplementation) group and a high-efficiency group with $17.4 \mathrm{~L}$ or more, the latter experienced significantly reduced overall mortality rate $(\mathrm{p}=0.03)$.

The ESHOL (Estudio de Supervivencia de Hemodiafiltración On-Line) Study [57], a randomized clinical trial comparing high-efficiency online HDF with HD, reported a $30 \%$ reduction in overall mortality (hazard ratio [HR], $0.70 ; 95 \%$ CI, $0.53-0.92 ; \mathrm{p}=0.01$ ) and a $33 \%$ reduction in CV mortality (HR, 0.67; 95\% CI, 0.44-1.01; $\mathrm{p}=0.06$ ) in the high-flow online HDF. Of the patients in the HD group, 8.1\% used low-flux HD membranes.

In both the Turkish OL-HDF and FRENCHIE studies, no differences in overall hospitalization rates were observed between the two groups, but in the ESHOL Study, the hospitalization rate was lower in the high-flow online HDF group (RR, 0.78; 95\% CI, 0.67-0.90; $\mathrm{p}<0.01$ ). In terms of quality of life, a meta-analysis performed on six prospective clinical trials, excluding observational studies [58-63], found no significant difference between the online HDF and HD groups.

\section{Chapter 4. Anticoagulation for the hemodialysis}

\section{Recommendation 4.1}

We recommend using unfractionated heparin (UFH) as the standard for systemic anticoagulation in HD patients without an increased bleeding risk because no differences could be found in the bleeding outcomes or circuit thrombosis between UFH and low-molecular-weight heparin (LMWH).

(Strong recommendation, low quality of evidence)

$\mathrm{UFH}$ is a conventional anticoagulant for HD in patients without active bleeding, a recent history of bleeding events, moderate to severe thrombocytopenia or heparin allergy. Typically, a loading dose of 1,000 to 2,000 units is administered at the start of HD, followed by a continuous infusion of 500 to 1,500 units per hour that is stopped approximately 30 minutes before the end of the HD session. The heparin dose can be adjusted empirically according to the clinical situation. Compared to UFH, LMWH, which can be administered as a bolus, has been shown to produce superior lipid profiles and less osteoporosis, and its use in HD patients in Europe is increasing [64]. We intended to verify whether LMWH could reduce bleeding events or HD circuit thrombosis compared to the conventional UFH in HD patients without higher bleeding risks.

Three meta-analyses that addressed the efficacy and safety of LMWH and UFH were identified at the time of literature search [65-67]. We selected clinical studies with parallel or cross-over designs that randomly allocated patients on HD or HDF into LMWH and UFH groups over a period of at least one month. Several studies were excluded from the analysis because of the following reasons: a lessthan-1-week study period (Borm et al. [68], Koutsikos et al. [69] in the meta-analysis by Lim et al. [66] and Palamaner Subash Shantha et al. [67]); a dose-finding study design (Ryan et al. [70]); and no random allocation (Al-Saran et al. [71], Bramham et al. [72], Yang et al. [73] in a meta-analysis by Lazrak et al. [65], and Sabry et al. [74]). A meta-analysis was performed using six studies [75-80], although the poor blinding in these studies produced only moderate levels of evidence. The RR for any bleeding events was 0.74 (95\% CI, 0.24-2.31), indicating no difference between the LMWH and UFH groups. The reported cases of major bleeding 
were too low to perform subgroup analyses. Circuit thrombosis was defined as the number of cases of clotting in the dialyzer and circuit lines. Meta-analysis using three studies $[76,77,79]$ resulted in an RR of 0.99 (95\% CI, 0.56-1.77) for the LMWH group compared with UFH group, indicating no difference between the two anticoagulants. However, the level of evidence was assessed to be low due to heterogeneity among the studies and possible risks of bias.

\section{Recommendation 4.2}

1. We recommend not to use heparin for anticoagulation in HD patients with a high risk of bleeding.

(Against recommendation, low quality of evidence)

2. We suggest using nafamostat mesylate, instead of heparin, for anticoagulation in HD patients with a high risk of bleeding.

(Conditional recommendation, low quality of evidence)

Only a few studies conducted in Korea present low-level evidence for anticoagulation strategies for the HD patients with a risk of bleeding.

In a multi-center phase III trial assessing the influence of the anticoagulation efficacy and safety of nafamostat [81], $58 \mathrm{HD}$ patients were considered to be at high risk of bleeding due to hemorrhagic complications, including postoperative status and gastrointestinal bleeding. Among 49 patients assessed during their clinical course, none experienced progression of preexisting hemorrhagic lesions while using nafamostat, and an improvement in preexisting lesions was evident in 37 patients (71\%). In a cross-over arm involving the use of heparin in the same patients at preoperative stages or at recovery from hemorrhagic complication, aggravation of a preexisting lesion was observed in a single patient (4\%); Only six patients (28\%) experienced improvement in preexisting lesions, while 15 patients (68\%) remained stationary. Nafamostat also proved to be superior to heparin in the degrees of residual blood in the dialyzer and blood clotting in the venous drip chamber. The incidence of adverse reactions was comparable in both groups.

In a randomized trial conducted in a single center in Korea [82], 17 HD patients with intracerebral hemorrhages were divided into two groups; one treated with heparin (n $=9)$, and the other with nafamostat $(n=8)$. Follow-up imaging of hemorrhagic lesions with computed tomography revealed that, compared with heparin, nafamostat signifi- cantly prevented the aggravation of preexisting hemorrhagic lesions ( $p=0.02$ ), while no specific descriptions of blood clots or the adverse events were presented.

Despite the lack of large-scale trials, we recommend not using heparin as an anticoagulant in HD patients with a high risk of bleeding, based on limited data that use of heparin may aggravate preexisting hemorrhagic lesions. Provided that regional anticoagulation with nafamostat efficiently prevents both aggravations of preexisting lesion and thrombosis in the extracorporeal blood circuits, we suggest the use of nafamostat, instead of heparin, for anticoagulation in HD patients at high risk of bleeding.

\section{Chapter 5. Volume and fluid status in hemodialysis patients}

\section{Recommendation 5.1}

1. We suggest that the weight-gain ratio between dialysis sessions not exceed $4 \%$ compared with the dry weight before dialysis.

(Strong recommendation, moderate quality of evidence)

2. We consider it reasonable that patients whose body weight before dialysis exceeds $4 \%$ compared with the dry weight require an assessment of excess body fluids, dietary compliance, and nutritional status along with the provision of dietary education.

(Expert consensus)

Excessive weight gain between dialysis sessions can lead to excess fluid volume and increase CV events and mortality by inducing excessive ultrafiltration $[83,84]$. However, because weight gain between dialysis sessions is indicative of adequate nutritional intake, nephrologists should use a multifactorial approach to the evaluation of patients with weight gain between dialysis sessions. Both the United States Renal Data System (USRDS) Study [85] and the DOPPS (Dialysis Outcomes and Practice Patterns Study) [86], large-scale observational studies in the early 2000s, reported that if the rate of weight gain between dialysis is excessively high compared to the dry weight, the risk of death is significantly higher than that of the control group. The USRDS Study reported that the risk of death was higher in patients with an interdialytic weight gain [IDWG] of $>4.8 \%$ compared with a control group (IDWG $\leq 2.3 \%$ ). For patients in the DOPPS, an IDWG of $>5.7 \%$ was considered a high risk compared with an IDWG of $\leq 5.7 \%$ 
in the control group. Based on these results, the 2015 dialysis treatment guidelines in Japan recommended a weight-gain ratio of less than $6 \%$ between dialysis sessions. However, the ultrafiltration rate per time of dialysis was not adjusted in these studies, the effect size of the mortality risk was small, and the definition of IDWG between dialysis sessions was not unified [83,84].

Weight gain between dialysis sessions is closely correlated with chronic volume overload, but the two concepts are not identical. Recent research suggests that, in patients with large weight gain during dialysis, there is a need to assess body-fluid levels simultaneously using different methods such as bioimpedance spectroscopy [87], correcting for anemia and nutritional status $[88,89]$, and suggesting individualized approaches. The study included 38,614 HD patients who underwent total-body-fluid assessments. Even if the IDWG between dialysis was low ( $2.4 \%$ or less), the patients with chronic volume overload experienced significantly higher mortality [87]. As a result of the 2017 Japan DOPPS, in the group with a serum albumin level of $3.8 \mathrm{~g} / \mathrm{dL}$ or less, the association with death was significant only in the group with a weight gain between dialysis sessions of less than $2.4 \%$ [88]. In a study by Lee et al. [90], the weight-gain ratio between dialysis sessions was $4.0 \%$ in a dialysis group compared with $2.0 \%$ in a control group, with the dialysis group showing a significant CV event risk with an HR of 1.93 compared with that of a control group after adjustment for residual renal function. In addition, the frequency of intradialytic hypotension during dialysis increased significantly from $3 \%$ or more of IDWG, and this phenomenon during dialysis was associated with death [91]. After an observational study of DOPPS on the effect of weight gain between dialysis sessions on prognosis was published in 2003, recent trends and prognosis of weight gain between dialysis sessions were published in 2017 [92]. The 2017 DOPPS study, which included approximately 22,000 patients, showed that, compared with results from 2003, the number of patients with a high rate of weight gain between dialysis sessions was decreasing. Nephrologists and dialysis staff should examine whether patients with excessive weight gain between dialysis sessions have poor compliance with a low-salt diet and water restrictions, and whether these cause excessive volume overload $[86,93,94]$. Conversely, patients with a low IDWG should be assessed for their nutritional status and need for greater intake.

\section{Recommendation $\mathbf{5 . 2}$}

We suggest that the change of conventional dialysate sodium $(138-140 \mathrm{mEq} / \mathrm{L})$ to low dialysate sodium ( $<138 \mathrm{mEq} / \mathrm{L})$ to maintain adequate volume status. Attention should be paid to the possibility of developing intradialytic hypotension and muscle cramps while using low sodium dialysis.

(Conditional recommendation, moderate quality of evidence)

Sodium and water accumulation can lead to volume overload and hypertension, both of which are major risk factors for left ventricular hypertrophy [95-98]. In dialysis patients, antihypertensive drugs and ultrafiltration are the treatment of choice to remove volume overload, which is often not treated in clinical situations [99,100]. Katzarski et al. [101] reported that $90 \%$ of patients could control blood pressure without antihypertensive drugs if patients receive long HD $(3 \times 8$ hours/week $)$ and maintain an ideal healthy weight. In addition, some studies, which increased the frequency of dialysis to above usual levels, effectively controlled blood pressure, and edema and left ventricular hypertrophy were also improved [99,102,103].

However, increasing the frequency and duration of dialysis is subject to medical insurance restrictions. Lowering sodium dialysate levels below conventional levels is one method of removing sodium and water. Even at conventional sodium concentrations in dialysate, sodium moves back into the body, increasing blood pressure and water retention and leading to weight gain between dialysis [104]. According to a report studied in Korea, the sodium concentration of the dialysate was $140 \mathrm{mEq} / \mathrm{L}, 23 \% ; 138 \mathrm{mEq} / \mathrm{L}$, 64\%; and 136, 137, and $139 \mathrm{mEq} / \mathrm{L}$ [105].

Recently, Dunlop et al. [106] published a meta-analysis comparing low sodium dialysate levels ( $\mathrm{Na}$ of $<138 \mathrm{mEq} / \mathrm{L}$ ) to neutral conditions ( $\mathrm{Na}$ of $138-140 \mathrm{mEq} / \mathrm{L}$ ) and high sodium dialysate (Na of $>140 \mathrm{mEq} / \mathrm{L}$ ) in HD patients. This study shows that a low sodium dialysate level was associated with decreased weight gain, but increased risks of hypotension [106].

We conducted a literature search to compare the effects of conventional and low sodium dialysate on IDWG. Three randomized control studies and five before-and-after studies were reviewed [107-114]. We found that low dialysate sodium-reduced IDWG (mean difference [MD], $-0.27 \mathrm{~kg}$; $95 \% \mathrm{CI},-0.57$ to $0.17 ; \mathrm{p}=0.01$ ), predialysis blood pressure (MD, $-3.52 ; 95 \% \mathrm{CI},-5.46$ to -1.57 ; $\mathrm{p}<0.01$ ) and use of antihypertensive medications (standardized MD, $-0.60 ; 95 \%$ 
$\mathrm{CI},-1.13$ to $-0.07 ; \mathrm{p}=0.03)$. Low dialysate sodium was associated with low serum sodium concentration (MD, -1.59 ; $95 \% \mathrm{CI},-2.40$ to $-0.78 ; \mathrm{p}<0.01)$. The use of low sodium dialysate comes with increased side effects, such as hypotension, muscle cramps, and headaches during dialysis. The meta-analysis revealed that the frequency of hypotension during dialysis was significantly increased (RR, 1.49; 95\% CI, 1.09-2.03; $\mathrm{p}=0.01$ ). This meta-analysis confirmed that low sodium dialysis solutions significantly reduced IDWG and blood pressure before dialysis compared with a group using conventional sodium dialysate.

\section{Chapter 6. Blood pressure control in hemodialysis patients}

\section{Recommendation 6.1}

1. There is insufficient evidence to assign optimal blood pressure target for HD patients.

(Inconclusive, very low quality of evidence)

2. We consider it reasonable that antihypertensive medications should be prescribed for hypertensive HD patients considering multi-factors.

(Expert consensus)

Lowering blood pressure significantly reduces CV morbidity and mortality rate in HD patients, which is a phenomenon similar to one associated with antihypertensive medications in the general population. However, no optimal blood pressure has been suggested [115]. Some traits require careful interpretation of the effects of lowering blood pressure. Most randomized controlled trials are based on a specific drug, not a target blood pressure. In a systematic review, it was difficult to pool blood pressure targets, because reductions in blood pressure achieved by patients varied widely among the trials, and also because baseline blood pressures were heterogenous among the studies. It is therefore insufficient to decide whether the effect of antihypertensive medication is from drug-specific effects or from reduced blood pressure under certain standards.

In one prospective observational cohort study performed in South Korea, a U-shaped HR pattern for patient mortality was observed among 2,299 HD patients over 4.5 median years of follow-up. The lowest risk was shown at 130-150 $\mathrm{mmHg}$ of systolic blood pressure. When continuous blood pressure was categorized, groups of patients with systol- ic blood pressure under $110 \mathrm{mmHg}$ and over $170 \mathrm{mmHg}$ were associated with an increased HR for mortality [116]. In a Western study based on 9,333 HD patients in an observational cohort with a median follow-up of 1.5 years, a similar U-shaped HR pattern of patient mortality was observed. However, the lowest risk was observed at close to $165 \mathrm{mmHg}$, which was different from the results of the Korean study [117]. Observational investigations of blood pressure and patient mortality among HD patients reported a U-shaped HR pattern, which represents an increased mortality risk at the tails of the blood pressure distribution. Nevertheless, this evidence is insufficient to suggest a consistent threshold of blood pressure at which an elevated mortality risk is likely. A multi-faceted approach is needed, because several factors can affect blood pressure treatment as confounders; these include interdialytic blood pressure variability [118], intradialytic antihypertensive drug removal through dialysis membranes [119], body-fluid changes [120], reduced vascular elasticity, and postdialysis blood pressure increment, which can also manifest as intradialytic hypertension [121].

\section{Recommendation 6.2}

We suggest lowering the dialysate temperature to reduce intradialytic hypotension.

(Conditional recommendation, moderate quality of evidence)

Intradialytic hypotension is a common complication and requires appropriate management because it affects the morbidity and mortality of HD patients. Several methods have been applied to the prevention of intradialytic hypotension. One is the lowering the dialysate temperature. Standard temperature dialysis typically involves maintaining the dialysate at $36.5^{\circ} \mathrm{C}-37.0^{\circ} \mathrm{C}$, which is similar to body temperature. Methods that lower the dialysate temperature are dialysis with a fixed reduction of dialysate temperature (usually $35.0^{\circ} \mathrm{C}-35.5^{\circ} \mathrm{C}$ ) and isothermic dialysis through body temperature monitoring using a biofeedback system [122].

According to seven randomized controlled trials [123-129] and three prospective studies [130-132], intradialytic hypotension incidence decreased when dialysis was performed by lowering the dialysate temperature [123-128,130,131]. Moreover, little change in blood pressure reduction was evident during or after dialysis, and the lowest blood pressure during dialysis was also higher than that of standard dialysis 
[123,124,126-132]. These effects were more apparent in patients who experience more frequent intradialytic hypotension [127]. Lowering the dialysate temperature resulted in a decrease in the incidence of intradialytic hypotension, decreased regional left ventricular dysfunction, and myocardial stunning [123,129]. Cold sensations or discomfort tended to strengthen when the dialysate temperature was lowered; but not enough to stop dialysis [123,129], nor there was a difference in symptoms such as shivering [128]. Instead, studies have reported that patients felt more energetic with a lower dialysate temperature and requested reduction of the dialysate temperature in the future $[127,131]$. In previous studies, the dialysis efficiency, assessed by Kt/V and the URR, did not differ by dialysate temperature $[127,128,130]$. However, no direct comparison was made of the effects of dialysis between a fixed reduction of dialysate temperature and isothermic dialysate. Most studies of dialysate temperature were randomized cross-over trials conducted in a relatively small number of patients for a short period of time. In addition, no studies have been reported with longterm follow-up results on CV disease and mortality, and a large-scale study is needed to evaluate the major long-term outcomes according to dialysate temperature.

\section{Chapter 7. Evaluating and monitoring hemodialysis patients}

\section{Recommendation 7.1}

1. We consider it reasonable to test dialysis adequacy at least every 3 months in patients on maintenance HD. (Expert consensus)

2. We consider it reasonable to perform complete blood count tests, liver function tests, and routine chemistry tests at least monthly in patients on maintenance HD.

(Expert consensus)

3. We consider it reasonable to test iron status, parathyroid hormone (PTH), and hemoglobin A1C (in diabetic patients) and perform a chest radiograph at least every 3 months in patients on maintenance HD.

(Expert consensus)

4. We consider it reasonable to test hepatitis viral markers and perform electrocardiography at least every 6 months in patients on maintenance HD.

(Expert consensus)
In patients undergoing $\mathrm{HD}$, the purpose of dialysis is to remove uremic substances and water caused by CKD, and to control uremic symptoms, maintain stable electrolyte balance, and prevent deterioration of nutritional status, thereby improving health and quality of life. Maintaining an adequate dialysis dose means maintaining the patient's well-being, adequate volume status, and balanced biochemical levels. Multiple studies have reported that dialysis adequacy improves patient survival and quality of life [43,133-136]. However, no randomized controlled trials or prospective observational studies report outcomes for test items and intervals in patients on maintenance HD. Moreover, we found no studies of Korean patients on maintenance HD. However, in a recently published retrospective study in Canada, monthly routine blood testing in HD patients was not associated with a lower risk of death, CV events, or hospitalizations compared with testing every 6 weeks [137]. This guideline recommends performing a test as described above in accordance with expert opinion, considering that most dialysis centers conduct blood tests monthly.

Previously published foreign practice guidelines recommend that dialysis doses be measured monthly, as most dialysis centers perform blood tests, including those for electrolytes, monthly and as tests performed in patients undergoing maintenance HD are uncomplicated and inexpensive $[138,139]$. The KDOQI guideline published in 2006 recommended that the dialysis dose be measured at regular intervals of no less than monthly (A). Less-frequent measurements may compromise the timeliness with which deficiencies in the delivered dose of HD are detected and therefore may delay implementation of corrective action [138]. European best practice guidelines published in 2007 also recommend that delivered dialysis doses should be measured at least monthly (opinion) [139]. The UK Renal Association CPG published in 2019, recommends measuring and monitoring dialysis doses on a monthly base for the majority of center-based dialysis patients (1B) [64]. However, in this guideline, we recommended that dialysis doses be measured at least every 3 months according to expert agreement, taking into account the medical reality and cost of testing in Korea.

In this guideline, monthly complete blood counts, liver function tests (including total protein and albumin levels), and routine blood chemistry (blood urea nitrogen, creat- 
inine, sodium, potassium, calcium, phosphate, uric acid, and glucose) are recommended. Most HD centers in Korea perform blood tests monthly. Moreover, the 2012 Kidney Disease: Improving Global Outcomes (KDIGO) CPG for anemia in CKD recommends measuring hemoglobin concentrations at least monthly in patients with grade $5 \mathrm{CKD}$ [140]. This guideline recommends applying those guidelines to Korean patients on maintenance HD, according to expert agreement.

The KDIGO 2017 CPG update for CKD-mineral bone disorder states that it is reasonable to monitor PTH levels every 3-6 months in patients with grade 5 CKD $[141,142]$. We recommend monitoring PTH levels at least every 3 months, according to expert agreement in this guideline. As other guidelines, including the KDIGO, suggest screening for hepatitis virus infection in patients on dialysis every 6 months [143-145], this guideline recommends screening for hepatitis viral markers at least every 6 months, according to expert agreement in this guideline.

\section{Chapter 8. Nonstandard setting of hemodialysis (elderly, children)}

\section{Recommendation 8.1}

1. We suggest that preparation for appropriate renal replacement therapy be considered for elderly patients who progress to ESKD.

(Conditional recommendation, moderate quality of evidence)

2. We consider it reasonable that in elderly patients with ESKD, the optimal treatment should find an individualized balance between appropriate renal replacement therapy and conservative treatment.

(Expert consensus)

With the advancement of renal replacement therapy, the overall survival rate of patients with ESKD is improving, but it is not yet clear whether renal replacement therapy offers any survival benefit in elderly patients compared with conservative treatment. Although randomized control studies are not available due to the nature of the study, comparing the dialysis group with the conservation treatment group makes it difficult to compare the selection bias of elderly patients with a relatively healthy group, the lead-time bias of the patients with dialysis, and the lack of studies of patients who perform conservative treatment. A meta-analysis of 89 observational studies from 1976 to 2014 on elderly patients with ESKD, including a total of 294,921 patients, reported a 1-year survival rate of $77.9 \%$ in the HD group and $70.6 \%$ in the conservative treatment group. Although the report that HD may have some benefits [146], it was unable to judge the role of conservative treatment because only 724 patients $(0.2 \%)$ were included in the conservative treatment group. In a 2017 meta-analysis, the dialysis group showed a superior survival rate compared with the conservative treatment group (HR, 0.53; 95\% CI 0.30-0.91; $\mathrm{p}=0.02$ ), but there was significant heterogeneity among studies [147]. Most of the studies before 2010 included in the meta-analysis were small and retrospective studies [148-150], and one small prospective study did not distinguish HD from peritoneal dialysis [151].

In prospective observational studies of elderly patients after 2015, dialysis treatment was associated with benefits compared with conservative treatment in entire patient groups [152-154], although comorbidities increased [152] and the benefit was not significant in patients older than 85 years [153] or 80 years [154]. In retrospective studies, the benefit of dialysis was greater than that of conservative treatment, but setting an appropriate control group would be important [155-157]. A Canadian study of reimbursement data using propensity-score matching showed a benefit of dialysis in the first 3 years (HR, 0.59; 95\% CI, 0.46-0.77; $\mathrm{p}<0.01$ ), but no difference between dialysis and conservative treatment was found after 3 years [157]. In this practice guideline, we conducted a meta-analysis of 11 studies in which the mean age of elderly patients in the dialysis group was $76.0 \pm 5.3$ years. The meta-analysis showed that dialysis was more beneficial regarding survival than conservative treatment in elderly patients (HR, 0.42; 95\% CI, 0.37-0.47; $\mathrm{p}<0.01$ ). As the evidence for survival gain by dialysis treatment grows $[158,159]$, preparations for appropriate renal replacement therapy are needed when elderly patients progress to ESKD.

\section{Recommendation $\mathbf{8 . 2}$}

1. For HD of children younger than 5 years old, we consider it reasonable that the minimal nurse-to-patient ratio be 1:1. (Expert consensus)

2. For HD of older children, we consider it reasonable that the minimal nurse-to-patient ratio be 1:2.

(Expert consensus) 
Dialysis in infants and children requires exceptional skill and expertise. Pediatric HD requires devices appropriate for the patient's body size, neonatal or pediatric dosages of medications, proper management of vascular access problems, and meticulous monitoring of volume status and vital signs. Infants and young children undergoing HD are sensitive to small changes in body water volume or blood pressure because their effective blood volume is smaller than that of adults [160]. As children may not recognize or verbally express the symptoms of side effects of $\mathrm{HD}$, vital signs should be measured more frequently, and patients need to be monitored more carefully than adults during pediatric HD. For safe HD in children, more frequent clinical assessment is necessary [161] and often requires a nurseto-patient ratio of 1:1 [162]. While there has been no CPG [163], a survey of clinical practices in the UK reported that a typical nurse-to-patient ratio was 1:1 for HD in children younger than 5 years old and 1:2-1:3 in the case of older children at most centers [164]. For HD in young children or patients with significant neurocognitive disability, a nurseto-patient ratio of 1:1 is required. An infant may need the care of two nurses. HD requiring isolation also needs one nurse for each patient. For children who can communicate or adolescents whose development is normal, a nurse-topatient ratio of 1:2 may be safe. For pediatric dialysis, there should be at least two registered nurses per duty, and a nurse-to-patient ratio should be 1:2 or higher [165].

\section{Additional information}

${ }^{1}$ Division of Nephrology, Department of Internal Medicine, Gachon University Gil Medical Center, Gachon University College of Medicine, Incheon, Republic of Korea

${ }^{2}$ Division of Nephrology, Department of Internal Medicine, Ulsan University Hospital, University of Ulsan College of Medicine, Ulsan, Republic of Korea

${ }^{3}$ Division of Nephrology, Department of Internal Medicine, Ewha Womans University Seoul Hospital, Ewha Womans College of Medicine, Seoul, Republic of Korea

${ }^{4}$ Division of Pediatric Nephrology, Department of Pediatrics, Seoul National University Children's Hospital, Seoul, Republic of Korea

${ }^{5}$ Division of Nephrology, Department of Internal Medicine, Chung-

Ang University Hospital, Seoul, Republic of Korea

${ }^{6}$ Division of Nephrology, Department of Internal Medicine, Soonchunhyang University Seoul Hospital, Seoul, Republic of Korea

${ }^{7}$ Division of Nephrology, Department of Internal Medicine, Pusan National University Hospital, Busan, Republic of Korea

${ }^{8}$ Asan Jin Internal Medicine Clinic, Seoul, Republic of Korea

${ }^{9}$ Division of Nephrology, Department of Internal Medicine,

Chonnam National University Hospital, Gwangju, Republic of Korea
${ }^{10}$ Division of Nephrology, Department of Internal Medicine, Seoul National University Bundang Hospital, Seongnam, Republic of Korea

${ }^{11}$ Division of Nephrology, Department of Internal Medicine, Kyungpook National University Chilgok Hospital, Daegu, Republic of Korea

${ }^{12}$ Truewords Dialysis Clinic, Incheon, Republic of Korea

${ }^{13}$ Division for Healthcare Technology Assessment Research, National Evidence-Based Healthcare Collaborating Agency, Seoul, Republic of Korea

${ }^{14}$ Department of Biostatistics, Korea University College of Medicine, Seoul, Republic of Korea

${ }^{15}$ Division of Nephrology, Department of Internal Medicine, Seoul National University Hospital, Seoul, Republic of Korea

\section{Access to the full-text version}

The full-text version of this CPG is available on the KSN website (http://www.ksn.or.kr, http://krcp-ksn.org)

\section{Conflicts of interest}

All authors have no conflicts of interest to declare. The Work Group has been making the best efforts to avoid any actual and potential conflicts of interest to ensure a neutral and fair process in guideline development. All members of the Work Group obtained a conflict-of-interest disclosure form before participating in the development of the CPG and when completing the CPG to determine whether there was a financial or non-financial conflict of interest. In the case of reports of corporate research sponsorship or consulting, detailed report contents were confirmed after review by the Work Group. To determine whether the amount of money and the content of the recommendation can be affected, and if an amount exceeding the standard may affect the content of the recommendation, we recommend that the opinion of the relevant member be excluded when determining the direction and strength of the recommendation. This principle was applied from the beginning to the end of the development.

\section{ORCID}

Ji Yong Jung, https://orcid.org/0000-0003-1271-8012

Kyung Don Yoo, https://orcid.org/0000-0001-6545-6517

Eunjeong Kang, https://orcid.org/ 0000-0002-2191-2784

Hee Gyung Kang, https://orcid.org/ 0000-0001-8323-5320

Su Hyun Kim, https://orcid.org/ 0000-0003-3382-528X 
Hyoungnae Kim, https://orcid.org/ 0000-0002-5359-0214

Hyo Jin Kim, https://orcid.org/0000-0001-9289-9073

Tae-Jin Park, https://orcid.org/ 0000-0003-2631-2953

Sang Heon Suh, https://orcid.org/0000-0003-3076-3466

Jong Cheol Jeong, https://orcid.org/0000-0003-0301-7644

Ji-Young Choi, https://orcid.org/ 0000-0002-9774-3665

Young-Hwan Hwang, https://orcid.org/0000-0001-8935-2659

Miyoung Choi, https://orcid.org/0000-0002-2424-9965

Yae Lim Kim, https://orcid.org/0000-0002-4316-9696

Kook-Hwan Oh, https://orcid.org/ 0000-0001-9525-2179

\section{References}

1. Cooper BA, Branley P, Bulfone L, et al. A randomized, controlled trial of early versus late initiation of dialysis. $N$ Engl J Med 2010;363:609-619.

2. Collins J, Cooper B, Branley P, et al. Outcomes of patients with planned initiation of hemodialysis in the IDEAL trial. Contrib Nephrol 2011;171:1-9.

3. Harris A, Cooper BA, Li JJ, et al. Cost-effectiveness of initiating dialysis early: a randomized controlled trial. Am J Kidney Dis 2011;57:707-715.

4. Whalley GA, Marwick TH, Doughty RN, et al. Effect of early initiation of dialysis on cardiac structure and function: results from the echo substudy of the IDEAL trial. Am J Kidney Dis 2013;61:262-270.

5. Korevaar JC, Jansen MA, Dekker FW, et al. When to initiate dialysis: effect of proposed US guidelines on survival. Lancet 2001;358:1046-1050.

6. Traynor JP, Simpson K, Geddes CC, Deighan CJ, Fox JG. Early initiation of dialysis fails to prolong survival in patients with endstage renal failure. J Am Soc Nephrol 2002;13:2125-2132.

7. Kazmi WH, Gilbertson DT, Obrador GT, et al. Effect of comorbidity on the increased mortality associated with early initiation of dialysis. Am J Kidney Dis 2005;46:887-896.

8. Hwang SJ, Yang WC, Lin MY, Mau LW, Chen HC; Taiwan Society of Nephrology. Impact of the clinical conditions at dialysis initiation on mortality in incident haemodialysis patients: a national cohort study in Taiwan. Nephrol Dial Transplant 2010;25:26162624.

9. Lassalle M, Labeeuw M, Frimat L, et al. Age and comorbidity may explain the paradoxical association of an early dialysis start with poor survival. Kidney Int 2010;77:700-707.

10. Wright S, Klausner D, Baird B, et al. Timing of dialysis initiation and survival in ESRD. Clin J Am Soc Nephrol 2010;5:1828-1835.
11. Clark WF, Na Y, Rosansky SJ, et al. Association between estimated glomerular filtration rate at initiation of dialysis and mortality. CMAJ 2011;183:47-53.

12. Chang JH, Rim MY, Sung J, et al. Early start of dialysis has no survival benefit in end-stage renal disease patients. J Korean Med Sci 2012;27:1177-1181.

13 .Zhang Y, Hu C, Bian Z, Chen P. Impact of timing of initiation of dialysis on long-term prognosis of patients undergoing hemodialysis. Exp Ther Med 2018;16:1209-1215.

14. Susantitaphong P, Altamimi S, Ashkar M, et al. GFR at initiation of dialysis and mortality in CKD: a meta-analysis. Am J Kidney Dis 2012;59:829-840.

15. Kim DH, Park JI, Lee JP, et al. The effects of vascular access types on the survival and quality of life and depression in the incident hemodialysis patients. Ren Fail 2020;42:30-39.

16. Ozeki T, Shimizu H, Fujita Y, et al. The type of vascular access and the incidence of mortality in Japanese dialysis patients. Intern Med 2017;56:481-485.

17. Bae E, Lee H, Kim DK, et al. Autologous arteriovenous fistula is associated with superior outcomes in elderly hemodialysis patients. BMC Nephrol 2018;19:306.

18. Yeh LM, Chiu SY, Lai PC. The impact of vascular access types on hemodialysis patient long-term survival. Sci Rep 2019;9:10708.

19. Lok CE, Huber TS, Lee T, et al. KDOQI Clinical Practice Guideline for Vascular Access: 2019 update. Am J Kidney Dis 2020;75(4 Suppl 2):S1-S164.

20. Shechter SM, Skandari MR, Zalunardo N. Timing of arteriovenous fistula creation in patients With CKD: a decision analysis. Am J Kidney Dis 2014;63:95-103.

21. Dember LM, Lacson E Jr, Brunelli SM, et al. The TiME trial: a fully embedded, cluster-randomized, pragmatic trial of hemodialysis session duration. J Am Soc Nephrol 2019;30:890-903.

22. Lowrie EG, Laird NM, Parker TF, Sargent JA. Effect of the hemodialysis prescription of patient morbidity: report from the National Cooperative Dialysis Study. N Engl J Med 1981;305:11761181.

23. Brunelli SM, Chertow GM, Ankers ED, Lowrie EG, Thadhani R. Shorter dialysis times are associated with higher mortality among incident hemodialysis patients. Kidney Int 2010;77:630636.

24. Flythe JE, Curhan GC, Brunelli SM. Shorter length dialysis sessions are associated with increased mortality, independent of body weight. Kidney Int 2013;83:104-113.

25. Shinzato T, Nakai S, Akiba T, et al. Survival in long-term haemodialysis patients: results from the annual survey of the Jap- 
anese Society for Dialysis Therapy. Nephrol Dial Transplant 1997;12:884-888.

26. Tentori F, Zhang J, Li Y, et al. Longer dialysis session length is associated with better intermediate outcomes and survival among patients on in-center three times per week hemodialysis: results from the Dialysis Outcomes and Practice Patterns Study (DOPPS). Nephrol Dial Transplant 2012;27:4180-4188.

27. Shemin D, Bostom AG, Laliberty P, Dworkin LD. Residual renal function and mortality risk in hemodialysis patients. Am J Kidney Dis 2001;38:85-90.

28. Charra B, Calemard M, Laurent G. Importance of treatment time and blood pressure control in achieving long-term survival on dialysis. Am J Nephrol 1996;16:35-44.

29. Marshall MR, Byrne BG, Kerr PG, McDonald SP. Associations of hemodialysis dose and session length with mortality risk in Australian and New Zealand patients. Kidney Int 2006;69:1229-1236.

30. Hwang HS, Hong YA, Yoon HE, et al. Comparison of clinical outcome between twice-weekly and thrice-weekly hemodialysis in patients with residual kidney function. Medicine (Baltimore) 2016;95:e2767.

31. Lin X, Gu L, Zhu M, et al. Clinical outcome of twice-weekly hemodialysis patients with long-term dialysis vintage. Kidney Blood Press Res 2018;43:1104-1112.

32. Sun Y, Wang Y, Yu W, Zhuo Y, Yuan Q, Wu X. Association of dose and frequency on the survival of patients on maintenance of hemodialysis in China: a Kaplan-Meier and Cox-proportional hazard model analysis. Med Sci Monit 2018;24:5329-5337.

33. Held PJ, Port FK, Wolfe RA, et al. The dose of hemodialysis and patient mortality. Kidney Int 1996;50:550-556.

34. Bloembergen WE, Stannard DC, Port FK, et al. Relationship of dose of hemodialysis and cause-specific mortality. Kidney Int 1996;50:557-565.

35. Chertow GM, Owen WF, Lazarus JM, Lew NL, Lowrie EG. Exploring the reverse J-shaped curve between urea reduction ratio and mortality. Kidney Int 1999;56:1872-1878.

36. Wolfe RA, Ashby VB, Daugirdas JT, Agodoa LY, Jones CA, Port FK. Body size, dose of hemodialysis, and mortality. Am J Kidney Dis 2000;35:80-88.

37. Port FK, Ashby VB, Dhingra RK, Roys EC, Wolfe RA. Dialysis dose and body mass index are strongly associated with survival in hemodialysis patients. J Am Soc Nephrol 2002;13:1061-1066.

38. Salahudeen AK, Dykes P, May W. Risk factors for higher mortality at the highest levels of spKt/V in haemodialysis patients. Nephrol Dial Transplant 2003;18:1339-1344.

39. Termorshuizen F, Dekker FW, van Manen JG, et al. Relative contribution of residual renal function and different measures of adequacy to survival in hemodialysis patients: an analysis of the Netherlands Cooperative Study on the Adequacy of Dialysis (NECOSAD)-2. J Am Soc Nephrol 2004;15:1061-1070.

40. Port FK, Wolfe RA, Hulbert-Shearon TE, McCullough KP, Ashby VB, Held PJ. High dialysis dose is associated with lower mortality among women but not among men. Am J Kidney Dis 2004; 43:1014-1023.

41. Ramirez SP, Kapke A, Port FK, et al. Dialysis dose scaled to body surface area and size-adjusted, sex-specific patient mortality. Clin J Am Soc Nephrol 2012;7:1977-1987.

42. Hong WP, Lee YJ. The association of dialysis adequacy, body mass index, and mortality among hemodialysis patients. $B M C$ Nephrol 2019;20:382.

43. Eknoyan G, Beck GJ, Cheung AK, et al. Effect of dialysis dose and membrane flux in maintenance hemodialysis. $N$ Engl J Med 2002;347:2010-2019.

44. Locatelli F, Martin-Malo A, Hannedouche T, et al. Effect of membrane permeability on survival of hemodialysis patients. J Am Soc Nephrol 2009;20:645-654.

45. Asci G, Tz H, Ozkahya M, et al. The impact of membrane permeability and dialysate purity on cardiovascular outcomes. J Am Soc Nephrol 2013;24:1014-1023.

46. Ayli M, Ayli D, Azak A, et al. The effect of high-flux hemodialysis on dialysis-associated amyloidosis. Ren Fail 2005;27:31-34.

47. Chazot C, Kirchgessner J, Pham J, et al. Effect of membrane permeability on cardiovascular risk factors and $\beta 2 \mathrm{~m}$ plasma levels in patients on long-term haemodialysis: a randomised crossover trial. Nephron 2015;129:269-275.

48. Klemm A, Franke C, Busch M, et al. Influence of hemodialysis membrane permeability on serum levels of advanced glycation end products (AGEs) and homocysteine metabolites. Clin Nephrol 2004;61:191-197.

49. Küchle C, Fricke H, Held E, Schiffl H. High-flux hemodialysis postpones clinical manifestation of dialysis-related amyloidosis. Am J Nephrol 1996;16:484-488.

50. Lang SM, Bergner A, Töpfer M, Schiffl H. Preservation of residual renal function in dialysis patients: effects of dialysis-technique-related factors. Perit Dial Int 2001;21:52-57.

51. Li PK, Cheng YL, Leung CB, et al. Effect of membrane permeability on inflammation and arterial stiffness: a randomized trial. Clin J Am Soc Nephrol 2010;5:652-658.

52. Locatelli F, Andrulli S, Pecchini F, et al. Effect of high-flux dialysis on the anaemia of haemodialysis patients. Nephrol Dial Transplant 2000;15:1399-1409. 
53. Locatelli F, Mastrangelo F, Redaelli B, et al. Effects of different membranes and dialysis technologies on patient treatment tolerance and nutritional parameters. The Italian Cooperative Dialysis Study Group. Kidney Int 1996;50:1293-1302.

54. Simon P, Ang KS, Cam G, Benziane A, Bonn F. Indices of adequate dialysis in patients hemodialyzed with AN 69 membrane. Kidney Int Suppl 1993;41:S291-S295.

55. Ok E, Asci G, Toz H, et al. Mortality and cardiovascular events in online haemodiafiltration (OL-HDF) compared with high-flux dialysis: results from the Turkish OL-HDF Study. Nephrol Dial Transplant 2013;28:192-202.

56. Morena M, Jaussent A, Chalabi L, et al. Treatment tolerance and patient-reported outcomes favor online hemodiafiltration compared to high-flux hemodialysis in the elderly. Kidney Int 2017;91:1495-1509.

57. Maduell F, Moreso F, Pons M, et al. High-efficiency postdilution online hemodiafiltration reduces all-cause mortality in hemodialysis patients. J Am Soc Nephrol 2013;24:487-497.

58. Suwabe T, Barrera-Flores FJ, Rodriguez-Gutierrez R, Ubara Y, Takaichi K. Effect of online hemodiafiltration compared with hemodialysis on quality of life in patients with ESRD: a systematic review and meta-analysis of randomized trials. PLoS One 2018;13:e0205037.

59. Kantartzi K, Panagoutsos S, Mourvati E, et al. Can dialysis modality influence quality of life in chronic hemodialysis patients?: low-flux hemodialysis versus high-flux hemodiafiltration: a cross-over study. Ren Fail 2013;35:216-221.

60. Karkar A, Abdelrahman M, Locatelli F. A randomized trial on health-related patient satisfaction level with high-efficiency online hemodiafiltration versus high-flux dialysis. Blood Purif 2015;40:84-91.

61. Mazairac AH, de Wit GA, Grooteman MP, et al. Effect of hemodiafiltration on quality of life over time. Clin J Am Soc Nephrol 2013;8:82-89.

62. Smith JR, Zimmer N, Bell E, Francq BG, McConnachie A, Mactier R. A randomized, single-blind, crossover trial of recovery time in high-flux hemodialysis and hemodiafiltration. Am J Kidney Dis 2017;69:762-770.

63. Ward RA, Schmidt B, Hullin J, Hillebrand GF, Samtleben W. A comparison of on-line hemodiafiltration and high-flux hemodialysis: a prospective clinical study. J Am Soc Nephrol 2000;11:2344-2350.

64. Ashby D, Borman N, Burton J, et al. Renal Association Clinical Practice Guideline on Haemodialysis. BMC Nephrol 2019;20:379.

65. Lazrak HH, René É, Elftouh N, Leblanc M, Lafrance JP. Safety of low-molecular-weight heparin compared to unfractionated heparin in hemodialysis: a systematic review and meta-analysis. BMC Nephrol 2017;18:187.

66. Lim W, Cook DJ, Crowther MA. Safety and efficacy of low molecular weight heparins for hemodialysis in patients with end-stage renal failure: a meta-analysis of randomized trials. J Am Soc Nephrol 2004;15:3192-3206.

67. Palamaner Subash Shantha G, Kumar AA, Sethi M, Khanna RC, Pancholy SB. Efficacy and safety of low molecular weight heparin compared to unfractionated heparin for chronic outpatient hemodialysis in end stage renal disease: systematic review and meta-analysis. PeerJ 2015;3:e835.

68. Borm JJ, Krediet R, Sturk A, ten Cate JW. Heparin versus low molecular weight heparin K 2165 in chronic hemodialysis patients: a randomized cross-over study. Haemostasis 1986;16 Suppl 2:59-68.

69. Koutsikos D, Fourtounas C, Kapetanaki A, et al. A cross-over study of a new low molecular weight heparin (Logiparin) in hemodialysis. Int J Artif Organs 1996;19:467-471.

70. Ryan KE, Lane DA, Flynn A, Shepperd J, Ireland HA, Curtis JR. Dose finding study of a low molecular weight heparin, Innohep, in haemodialysis. Thromb Haemost 1991;66:277-282.

71. Al-Saran KA, Sabry A, Taha M, Ghafour MA, Al Fawzan F. Profile of low molecular weight tinzaparin sodium for anticoagulation during hemodialysis. Saudi J Kidney Dis Transpl 2010;21:43-49.

72. Bramham K, Varrier M, Asgari E, Makanjuola D. Comparison of Tinzaparin and unfractionated heparin as anticoagulation on haemodialysis: equal safety, efficacy and economical parity. Nephron Clin Pract 2008;110:c107-c113.

73. Yang C, Wu T, Huang C. Low molecular weight heparin reduces triglyceride, VLDL and cholesterol/HDL levels in hyperlipidemic diabetic patients on hemodialysis. Am J Nephrol 1998;18:384390.

74. Sabry A, Taha M, Nada M, Al Fawzan F, Alsaran K. Anticoagulation therapy during haemodialysis: a comparative study between two heparin regimens. Blood Coagul Fibrinolysis 2009;20:57-62.

75. Bambauer R, Rücker S, Weber U, Köhler M. Comparison of low molecular weight heparin and standard heparin in hemodialysis. ASAIO Trans 1990;36:M646-M649.

76. Lord H, Jean N, Dumont M, Kassis J, Leblanc M. Comparison between tinzaparin and standard heparin for chronic hemodialysis in a Canadian center. Am J Nephrol 2002;22:58-66.

77. Nurmohamed MT, ten Cate J, Stevens P, Hoek JA, Lins RL, ten Cate JW. Long-term efficacy and safety of a low molecular 
weight heparin in chronic hemodialysis patients: a comparison with standard heparin. ASAIO Trans 1991;37:M459-M461.

78. Saltissi D, Morgan C, Westhuyzen J, Healy H. Comparison of low-molecular-weight heparin (enoxaparin sodium) and standard unfractionated heparin for haemodialysis anticoagulation. Nephrol Dial Transplant 1999;14:2698-2703.

79. Schrader J, Stibbe W, Armstrong VW, et al. Comparison of low molecular weight heparin to standard heparin in hemodialysis/ hemofiltration. Kidney Int 1988;33:890-896.

80. Stefoni S, Cianciolo G, Donati G, et al. Standard heparin versus low-molecular-weight heparin: a medium-term comparison in hemodialysis. Nephron 2002;92:589-600.

81. Kim HC, Han SY, Kim HK, et al. A multi-center phase III clinical trial to assess the influence to bleeding and anticoagulant effect of nafamostat mesilate (Futhan) in hemodialysis patients with high bleeding-risk. Korean J Nephrol 2004;23:920- 926.

82. Yang JW, Han BG, Kim BR, et al. Superior outcome of nafamostat mesilate as an anticoagulant in patients undergoing maintenance hemodialysis with intracerebral hemorrhage. Ren Fail 2009;31:668-675.

83. Kalantar-Zadeh K, Regidor DL, Kovesdy CP, et al. Fluid retention is associated with cardiovascular mortality in patients undergoing long-term hemodialysis. Circulation 2009;119:671-679.

84. Stegmayr BG, Brannstrom M, Bucht S, et al. Minimized weight gain between hemodialysis contributes to a reduced risk of death. Int J Artif Organs 2006;29:675-680.

85. Foley RN, Herzog CA, Collins AJ; United States Renal Data System. Blood pressure and long-term mortality in United States hemodialysis patients: USRDS Waves 3 and 4 Study. Kidney Int 2002;62:1784-1790.

86. Saran R, Bragg-Gresham JL, Rayner HC, et al. Nonadherence in hemodialysis: associations with mortality, hospitalization, and practice patterns in the DOPPS. Kidney Int 2003;64:254-262.

87. Hecking M, Moissl U, Genser B, et al. Greater fluid overload and lower interdialytic weight gain are independently associated with mortality in a large international hemodialysis population. Nephrol Dial Transplant 2018;33:1832-1842.

88. Kurita N, Hayashino Y, Yamazaki S, et al. Revisiting interdialytic weight gain and mortality association with serum albumin interactions: the Japanese Dialysis Outcomes and Practice Pattern Study. J Ren Nutr 2017;27:421-429.

89. Toida T, Iwakiri T, Sato Y, Komatsu H, Kitamura K, Fujimoto S. Relationship between hemoglobin levels corrected by interdialytic weight gain and mortality in Japanese hemodialysis patients: Miyazaki Dialysis Cohort Study. PLoS One 2017;12:e0169117.

90. Lee MJ, Doh FM, Kim CH, et al. Interdialytic weight gain and cardiovascular outcome in incident hemodialysis patients. Am J Nephrol 2014;39:427-435.

91. Stefánsson BV, Brunelli SM, Cabrera C, et al. Intradialytic hypotension and risk of cardiovascular disease. Clin J Am Soc Nephrol 2014;9:2124-2132.

92. Wong MM, McCullough KP, Bieber BA, et al. Interdialytic weight gain: trends, predictors, and associated outcomes in the International Dialysis Outcomes and Practice Patterns Study (DOPPS). Am J Kidney Dis 2017;69:367-379.

93. Dantas LG, de Seixas Rocha M, Junior JA, Paschoalin EL, Paschoalin SR, Sampaio Cruz CM. Non-adherence to haemodialysis, interdialytic weight gain and cardiovascular mortality: a cohort study. BMC Nephrol 2019;20:402.

94. Leggat JE Jr, Orzol SM, Hulbert-Shearon TE, et al. Noncompliance in hemodialysis: predictors and survival analysis. Am J Kidney Dis 1998;32:139-145.

95. Dunlop JL, Vandal AC, de Zoysa JR, et al. Rationale and design of the Sodium Lowering In Dialysate (SoLID) trial: a randomised controlled trial of low versus standard dialysate sodium concentration during hemodialysis for regression of left ventricular mass. BMC Nephrol 2013;14:149.

96. Charra B, Calemard E, Ruffet M, et al. Survival as an index of adequacy of dialysis. Kidney Int 1992;41:1286-1291.

97. London GM, Pannier B, Guerin AP, et al. Alterations of left ventricular hypertrophy in and survival of patients receiving hemodialysis: follow-up of an interventional study. J Am Soc Nephrol 2001;12:2759-2767.

98. Mominadam S, Ozkahya M, Kayikcioglu M, et al. Interdialytic blood pressure obtained by ambulatory blood pressure measurement and left ventricular structure in hypertensive hemodialysis patients. Hemodial Int 2008;12:322-327.

99. FHN Trial Group, Chertow GM, Levin NW, et al. In-center hemodialysis six times per week versus three times per week. $N$ Engl J Med 2010;363:2287-2300.

100. Culleton BF, Walsh M, Klarenbach SW, et al. Effect of frequent nocturnal hemodialysis vs conventional hemodialysis on left ventricular mass and quality of life: a randomized controlled trial. JAMA 2007;298:1291-1299.

101. Katzarski KS, Charra B, Luik AJ, et al. Fluid state and blood pressure control in patients treated with long and short haemodialysis. Nephrol Dial Transplant 1999;14:369-375.

102. Wald R, Yan AT, Perl J, et al. Regression of left ventricular mass following conversion from conventional hemodialysis to 
thrice weekly in-centre nocturnal hemodialysis. BMC Nephrol 2012;13:3.

103. Chan CT, Floras JS, Miller JA, Richardson RM, Pierratos A. Regression of left ventricular hypertrophy after conversion to nocturnal hemodialysis. Kidney Int 2002;61:2235-2239.

104. Marshall MR, Dunlop JL. Are dialysate sodium levels too high? Semin Dial 2012;25:277-283.

105. Kim SM, Kim JG, Shin JH, et al. The effects of low sodium dialysate in hemodialysis patients. Korean J Nephrol 2011;30:53-60.

106. Dunlop JL, Vandal AC, Marshall MR. Low dialysate sodium levels for chronic haemodialysis. Cochrane Database Syst Rev 2019;1:CD011204.

107. Beduschi GC, Telini LS, Caramori JC, Martin LC, Barretti P. Effect of dialysate sodium reduction on body water volume, blood pressure, and inflammatory markers in hemodialysis patients: a prospective randomized controlled study. Ren Fail 2013;35:742-747.

108. Boquin E, Parnell S, Grondin G, et al. Crossover study of the effects of different dialysate sodium concentrations in large surface area, short-term dialysis. Proc Clin Dial Transplant Forum 1977;7:48-52.

109. Liu J, Sun F, Ma LJ, Shen Y, Mei X, Zhou YL. Increasing dialysis sodium removal on arterial stiffness and left ventricular hypertrophy in hemodialysis patients. J Ren Nutr 2016;26:38-44.

110. Akyol A, Akdag S, Asker M, et al. Effects of lowered dialysate sodium on left ventricle function and brain natriuretic peptide in maintenance of hemodialysis patients. Hum Exp Toxicol 2017;36:128-134.

111. Arramreddy R, Sun SJ, Munoz Mendoza J, Chertow GM, Schiller B. Individualized reduction in dialysate sodium in conventional in-center hemodialysis. Hemodial Int 2012;16:473-480.

112. Kooman JP, Hendriks EJ, van Den Sande FM, Leumissen KM. Dialysate sodium concentration and blood pressure control in haemodialysis patients. Nephrol Dial Transplant 2000;15:554.

113. Sayarlioglu H, Erkoc R, Tuncer M, et al. Effects of low sodium dialysate in chronic hemodialysis patients: an echocardiographic study. Ren Fail 2007;29:143-146.

114. Zhou YL, Liu J, Ma LJ, et al. Effects of increasing diffusive sodium removal on blood pressure control in hemodialysis patients with optimal dry weight. Blood Purif 2013;35:209-215.

115. Heerspink HJ, Ninomiya T, Zoungas S, et al. Effect of lowering blood pressure on cardiovascular events and mortality in patients on dialysis: a systematic review and meta-analysis of randomised controlled trials. Lancet 2009;373:1009-1015.

116. Hannedouche T, Roth H, Krummel T, et al. Multiphasic effects of blood pressure on survival in hemodialysis patients. Kidney Int 2016;90:674-684.

117. Jhee JH, Park J, Kim H, et al. The optimal blood pressure target in different dialysis populations. Sci Rep 2018;8:14123.

118. Van Buren PN, Kim C, Toto R, Inrig JK. Intradialytic hypertension and the association with interdialytic ambulatory blood pressure. Clin J Am Soc Nephrol 2011;6:1684-1691.

119. Assimon MM, Brookhart MA, Fine JP, Heiss G, Layton JB, Flythe JE. A comparative study of carvedilol versus metoprolol initiation and 1-year mortality among individuals receiving maintenance hemodialysis. Am J Kidney Dis 2018;72:337-348.

120. Agarwal R, Alborzi P, Satyan S, Light RP. Dry-weight reduction in hypertensive hemodialysis patients (DRIP): a randomized, controlled trial. Hypertension 2009;53:500-507.

121. Zhang H, Preciado P, Wang Y, et al. Association of all-cause mortality with predialysis systolic blood pressure and its peridialytic change in chronic hemodialysis patients. Nephrol Dial Transplant 2020;35:1602-1608.

122. Tsujimoto Y, Tsujimoto H, Nakata Y, et al. Dialysate temperature reduction for intradialytic hypotension for people with chronic kidney disease requiring haemodialysis. Cochrane Database Syst Rev 2019;7:CD012598.

123. Selby NM, Burton JO, Chesterton LJ, McIntyre CW. Dialysis-induced regional left ventricular dysfunction is ameliorated by cooling the dialysate. Clin J Am Soc Nephrol 2006;1:1216-1225.

124. Chesterton LJ, Selby NM, Burton JO, McIntyre CW. Cool dialysate reduces asymptomatic intradialytic hypotension and increases baroreflex variability. Hemodial Int 2009;13:189-196.

125. Fine A, Penner B. The protective effect of cool dialysate is dependent on patients' predialysis temperature. Am J Kidney Dis 1996;28:262-265.

126. Jost CM, Agarwal R, Khair-el-Din T, Grayburn PA, Victor RG, Henrich WL. Effects of cooler temperature dialysate on hemodynamic stability in "problem" dialysis patients. Kidney Int 1993;44:606-612.

127. Ayoub A, Finlayson M. Effect of cool temperature dialysate on the quality and patients' perception of haemodialysis. Nephrol Dial Transplant 2004;19:190-194.

128. Maggiore Q, Pizzarelli F, Santoro A, et al. The effects of control of thermal balance on vascular stability in hemodialysis patients: results of the European randomized clinical trial. Am J Kidney Dis 2002;40:280-290.

129. Jefferies HJ, Burton JO, McIntyre CW. Individualised dialysate temperature improves intradialytic haemodynamics and abrogates haemodialysis-induced myocardial stunning, without 
compromising tolerability. Blood Purif 2011;32:63-68.

130. Cruz DN, Mahnensmith RL, Brickel HM, Perazella MA. Midodrine and cool dialysate are effective therapies for symptomatic intradialytic hypotension. Am J Kidney Dis 1999;33: 920-926.

131. Azar AT. Effect of dialysate temperature on hemodynamic stability among hemodialysis patients. Saudi J Kidney Dis Transpl 2009;20:596-603.

132. Hegbrant J, Thysell H, Mårtensson L, Nielsen AL, Lindberg BF. Delayed decrease in plasma levels of atrial natriuretic peptide during cold hemodialysis. Nephron 1994;68:427-432.

133. Owen WF Jr, Lew NL, Liu Y, Lowrie EG, Lazarus JM. The urea reduction ratio and serum albumin concentration as predictors of mortality in patients undergoing hemodialysis. $\mathrm{N} \mathrm{Engl} \mathrm{J}$ Med 1993;329:1001-1006.

134. Hakim RM, Breyer J, Ismail N, Schulman G. Effects of dose of dialysis on morbidity and mortality. Am J Kidney Dis 1994;23:661-669.

135. Parker TF 3rd, Husni L, Huang W, Lew N, Lowrie EG. Survival of hemodialysis patients in the United States is improved with a greater quantity of dialysis. Am J Kidney Dis 1994;23:670-680.

136. Collins AJ, Ma JZ, Umen A, Keshaviah P. Urea index and other predictors of hemodialysis patient survival. Am J Kidney Dis 1994;23:272-282.

137. Thomas A, Silver SA, Perl J, et al. The frequency of routine blood sampling and patient outcomes among maintenance hemodialysis recipients. Am J Kidney Dis 2020;75:471-479.

138. Hemodialysis Adequacy 2006 Work Group. Clinical practice guidelines for hemodialysis adequacy, update 2006. Am J Kidney Dis 2006;48 Suppl 1:S2-S90.

139. Tattersall J, Martin-Malo A, Pedrini L, et al. EBPG guideline on dialysis strategies. Nephrol Dial Transplant 2007;22 Suppl 2:ii5ii21.

140. Drüeke TB, Parfrey PS. Summary of the KDIGO guideline on anemia and comment: reading between the (guide)line(s). Kidney Int 2012;82:952-960.

141. Kidney Disease: Improving Global Outcomes (KDIGO) Hepatitis C Work Group. KDIGO clinical practice guideline for the diagnosis, evaluation, prevention, and treatment of chronic kidney disease-mineral and bone disorder (CKD-MBD). Kidney Int Suppl 2009;(113):S1-S130.

142. Kidney Disease: Improving Global Outcomes (KDIGO) Hepatitis C Work Group. KDIGO 2017 clinical practice guideline update for the diagnosis, evaluation, prevention, and treatment of chronic kidney disease-mineral and bone disorder (CKD-
MBD). Kidney Int Suppl (2011) 2017;7:1-59.

143. Kidney Disease: Improving Global Outcomes (KDIGO) Hepatitis C Work Group. KDIGO 2018 clinical practice guideline for the prevention, diagnosis, evaluation, and treatment of hepatitis C in chronic kidney disease. Kidney Int Suppl (2011) 2018;8:91-165.

144. Jardine M, Commons RJ, de Zoysa JR, et al. Kidney Health Australia: caring for Australasians with renal impairment guideline recommendations for infection control for haemodialysis units. Nephrology (Carlton) 2019;24:951-957.

145. Garthwaite E, Reddy V, Douthwaite S, Lines S, Tyerman K, Eccles J. Clinical practice guideline management of blood borne viruses within the haemodialysis unit. BMC Nephrol 2019;20:388.

146. Foote C, Kotwal S, Gallagher M, Cass A, Brown M, Jardine M. Survival outcomes of supportive care versus dialysis therapies for elderly patients with end-stage kidney disease: a systematic review and meta-analysis. Nephrology (Carlton) 2016;21:241253.

147. Wongrakpanich S, Susantitaphong P, Isaranuwatchai S, Chenbhanich J, Eiam-Ong S, Jaber BL. Dialysis therapy and conservative management of advanced chronic kidney disease in the elderly: a systematic review. Nephron 2017;137:178-189.

148. Smith C, Da Silva-Gane M, Chandna S, Warwicker P, Greenwood R, Farrington K. Choosing not to dialyse: evaluation of planned non-dialytic management in a cohort of patients with end-stage renal failure. Nephron Clin Pract 2003;95:c40-c46.

149. Joly D, Anglicheau D, Alberti C, et al. Octogenarians reaching end-stage renal disease: cohort study of decision-making and clinical outcomes. J Am Soc Nephrol 2003;14:1012-1021.

150. Murtagh FE, Marsh JE, Donohoe P, Ekbal NJ, Sheerin NS, Harris FE. Dialysis or not?: a comparative survival study of patients over 75 years with chronic kidney disease stage 5. Nephrol Dial Transplant 2007;22:1955-1962.

151. Carson RC, Juszczak M, Davenport A, Burns A. Is maximum conservative management an equivalent treatment option to dialysis for elderly patients with significant comorbid disease? Clin J Am Soc Nephrol 2009;4:1611-1619.

152. Brown MA, Collett GK, Josland EA, Foote C, Li Q, Brennan FP. CKD in elderly patients managed without dialysis: survival, symptoms, and quality of life. Clin J Am Soc Nephrol 2015;10:260-268.

153. Raman M, Middleton RJ, Kalra PA, Green D. Outcomes in dialysis versus conservative care for older patients: a prospective cohort analysis of stage 5 chronic kidney disease. PLoS One 
2018;13:e0206469.

154. van Loon IN, Goto NA, Boereboom FT, Verhaar MC, Bots ML, Hamaker ME. Quality of life after the initiation of dialysis or maximal conservative management in elderly patients: a longitudinal analysis of the Geriatric assessment in OLder patients starting Dialysis (GOLD) study. BMC Nephrol 2019;20:108.

155. Verberne WR, Geers AB, Jellema WT, Vincent HH, van Delden JJ, Bos WJ. Comparative survival among older adults with advanced kidney disease managed conservatively versus with dialysis. Clin J Am Soc Nephrol 2016;11:633-640.

156. Reindl-Schwaighofer R, Kainz A, Kammer M, Dumfarth A, Oberbauer R. Survival analysis of conservative vs. dialysis treatment of elderly patients with CKD stage 5. PLoS One 2017; 12:e0181345.

157. Tam-Tham H, Quinn RR, Weaver RG, et al. Survival among older adults with kidney failure is better in the first three years with chronic dialysis treatment than not. Kidney Int 2018;94: 582-588.

158. Pyart R, Aggett J, Goodland A, et al. Exploring the choices and outcomes of older patients with advanced kidney disease. PLoS One 2020;15:e0234309.

159. Tam-Tham H, Ravani P, Zhang J, et al. Association of initia- tion of dialysis with hospital length of stay and intensity of care in older adults with kidney failure. JAMA Netw Open 2020;3:e200222.

160. Kaur A, Davenport A. Hemodialysis for infants, children, and adolescents. Hemodial Int 2014;18:573-582.

161. Chand DH, Swartz S, Tuchman S, Valentini RP, Somers MJ. Dialysis in children and adolescents: the pediatric nephrology perspective. Am J Kidney Dis 2017;69:278-286.

162. Salerno AE, Weinstein A, Hanevold C. American Society of Pediatric Nephrology position paper: standard resources required for a pediatric nephrology practice. J Pediatr 2016; 174:254-259.

163. Jones L, Aldridge M. organization and management of a pediatric dialysis program. In: Warady B, Schaefer F, Alexander S, eds. Pediatric dialysis. 2nd ed. New York: Springer; 2012.

164. British Renal Society. The Renal Team: a multi-professional renal workforce plan for adults and children with renal disease. Recommendations of the National Renal Workforce Planning Group. Lichfield (UK): British Renal Society; 2002.

165. UniBritish Columbia Nurses' Union (BCNU). BCNU Position Statement on mandated nurse-patient ratios. Burnaby (BC): BCNU; 2011. 